\title{
A agricultura Sustentável: entre o ideal e a realidade
}

\author{
Maria Thereza Macedo Pedroso ${ }^{1}$
}

\section{Resumo}

O artigo discute a noção de sustentabilidade e sua evolução no período contemporâneo, discutindo ao final, especificamente, a proposta de uma "agricultura sustentável". O caminho metodológico para tal exame, na impossibilidade de examinar minuciosamente a vasta literatura a respeito, foi escolher dois livros recentes (2008 e 2010) de um autor considerado representativo neste campo de análise. Este autor é José Eli da Veiga e a primeira seção discute o argumento do autor, segundo o qual sustentabilidade, por enquanto, não passaria de uma palavra de ordem genérica, em transição para se transformar em um valor social. Segundo Veiga, somente quando a sustentabilidade se transformar em valor social é poderá deixar a retórica e sustentar novos esforços civilizatórios. Na segunda seção, também se fundando nos livros do autor, se discute a ideia de "desenvolvimento" e, por extensão, de "desenvolvimento sustentável", especialmente as suas possibilidades de ocorrência. A terceira parte do artigo esmiúça a noção de sustentabilidade e, finalmente, na quarta seção, o artigo trata especificamente da "agricultura sustentável".

Palavras-chave: Desenvolvimento. Desenvolvimento sustentável. Sustentabilidade como valor social. Agricultura sustentável.

\begin{abstract}
The article discusses the notion of sustainability and its evolution in contemporary times, also analyzing more specifically the proposal for "sustainable agriculture". Being impossible to scrutinize the vast literature dealing with the subject, the methodological strategy adopted was to choose two recent books (2008 and 2010) written by a leading author in this field. This author is José Eli da Veiga and the first section of the article discusses his argument that sustainability is actually nothing more than a generic idea, in transition to be transformed into a social value. According to him, only when sustainability becomes a social value it will not be a rhetorical notion anymore and will be capable to sustain new civilizational efforts. In the second section, also supported by Veiga's books, it is discussed the idea of "development" and it related notion, that of "sustainable development", in particular its possibilities of materialization. The third section of the article analyses specific details around the notion of sustainability. Finally, the fourth section deals in particular with the proposal of "sustainable agriculture".
\end{abstract}

\footnotetext{
${ }^{1}$ Pesquisadora, Embrapa Hortaliças (Gama, DF). maria.thereza@embrapa.br
} 
Keywords: Development. Sustainable development. Sustainability as a social value. Sustainable agriculture.

\section{Introdução}

Desde a década de 1970, irromperam com crescente visibilidade variadas manifestações sobre os impactos ambientais derivados do processo de expansão econômica do pós-guerra. Este padrão de crescimento produziu distintos arranjos sociais e político-institucionais, mas no plano das atividades econômicas foi convergindo para estruturas industriais e formas econômicas de uso dos recursos naturais, em especial (e primeiramente) nos países do chamado "capitalismo avançado". Um ponto inicial simbólico daquelas manifestações, identificado na literatura, tornou-se conhecido alguns anos antes, especialmente nos Estados Unidos: foi quando Rachel Carson, em seu livro "A primavera silenciosa" (1962), denunciou os efeitos do DDT na saúde humana e, em termos gerais, sugeriu que os formatos tecnológicos associados à agricultura moderna estariam produzindo diversas consequências deletérias ao meio ambiente.

$\mathrm{Na}$ década seguinte, em face da ampliação do conhecimento sobre outros impactos associados ao "padrão civilizatório" implantado durante os anos de intenso crescimento que se seguiram à Segunda Guerra, multiplicaram-se as manifestações sociais que reagiam àquelas consequências citadas e, desta forma, na prática, o que se chama atualmente de "movimento ambientalista" foi sendo fermentado na esteira dos turbulentos anos da década de 1970. No caso brasileiro, por exemplo, apenas como ilustração, uma ONG fundada em Porto Alegre (em 1971) acabou revelando o nome de José Lutzenberger, que depois se transformaria em ícone do movimento ambientalista brasileiro e, anos mais tarde, foi até mesmo ungido ao cargo de Ministro do Meio Ambiente, embora por curto período de tempo.

Esses antecedentes, aqui apenas esboçados como passageiras ilustrações, se constituíram no "caldo de cultura" de novos esforços na década seguinte, quando, em abril de 1987, o famoso "Relatório Brundtland", publicado na forma de um livro ("O nosso futuro comum") lançou uma expressão que se tornaria moeda corrente 
nos anos seguinte - a noção de sustentabilidade e seus derivativos que foram sendo elaborados posteriormente, do "crescimento sustentável" à "agricultura sustentável", da "sustentabilidade social" às "cidades sustentáveis", entre inúmeras outras possibilidades semânticas que foram sendo propostas ao longo dos anos seguintes à divulgação do Relatório.

Movido por amplo e crescente interesse, mas igualmente estimulado, em alguma medida, pelas tensões decorrentes dos magros anos da década de 1980, ou seja, um contexto econômico com baixas taxas de crescimento que sugeria a necessidade de buscar "novos caminhos" para a economia e para os arranjos sociais, a noção de sustentabilidade se espalhou como um rastilho de pólvora no último quarto de século, ampliando pesquisas, gerando debates, incentivando novas tecnologias e se afirmando como uma expressão corriqueira. Já no final da década de 1990, com a difusão das preocupações acerca das mudanças climáticas, a "busca da sustentabilidade" (por seus diversos ângulos) passou a ser obrigatória, inclusive, em programas governamentais.

Em face da desenvoltura sob a qual a palavra "sustentabilidade" expandiu-se, em todos os setores da vida social, seria esperado que seu significado adquirisse, gradualmente, indiscutível rigor conceitual e precisão terminológica, após tantos esforços para transformá-la de mera "noção", ainda largamente retórica, indicativa de objetivos gerais (senão genéricos) para um conceito propriamente dito, embutido em uma visão analítica mais rigorosa. Esta sequência de aperfeiçoamento de seu significado teria, de fato, ocorrido, neste período de tempo? A idéia geral e original de sustentabilidade (e seus correlatos) passou a adquirir, nos anos seguintes à sua emergência, um significado que sugira, claramente, as orientações práticas (da indústria e dos demais setores econômicos) destinadas a reconfigurar os formatos tecnológicos e os processos de produção de mercadorias? Em suma, deixou de ser noção e se transformou em conceito?

Este artigo pretende discutir a idéia de sustentabilidade e sua evolução, com um foco final mais determinado, ao final, para a expressão "agricultura sustentável". Para tanto, não podendo examinar exaustivamente a bibliografia existente, o que 
seria tarefa quase impossível, atualmente, face à inacreditável vastidão do tema, ${ }^{2}$ optou-se por um caminho indireto que, provavelmente, é logicamente correto e potencialmente produtivo para as finalidades aqui propostas. Para tanto, selecionouse um autor brasileiro que tem realizado notórios esforços em suas pesquisas e publicações sobre o assunto "sustentabilidade", sendo reconhecido como um dos especialistas brasileiros de maior respeitabilidade quando se discute o tema.

José Eli da Veiga, agrônomo de formação e economista "socioambiental" de longa experiência, professor do Departamento de Economia da FEA/USP, é este autor. Examinar-se-á neste artigo dois de seus livros mais representativos sobre o tema da sustentabilidade, ambos recentes e, portanto, ecoando também os debates internacionais que são acompanhados pelo autor. $O$ primeiro deles, "Desenvolvimento sustentável: o desafio do século XXI", publicado em 2008 (VEIGA, 2008), o qual foi seguido por outro livro mais recente, intitulado "Sustentabilidade. A legitimação de um novo valor" (VEIGA, 2010). ${ }^{3}$ São livros que trazem a resposta à pergunta antes sugerida? $\mathrm{O}$ autor aporta outro estatuto teórico para a palavra, permitindo que deixe de ser uma noção, largamente banalizada nos anos mais recentes, e contenha um significado rigoroso, a ponto de transformar-se em conceito?

$\mathrm{O}$ artigo é organizado em quatro seções. Primeiramente, é indicado que, segundo o autor, sustentabilidade é ainda uma noção, transitando de uma "palavra de ordem" lançada vinte e cinco atrás, para outro significado, talvez um possível e futuro valor social - aliás, esta transição sendo uma premissa, segundo José Eli da Veiga, para que possa enraizar-se nas práticas sociais e nos formatos econômicos das diferentes sociedades. A segunda parte problematiza, ainda seguindo os delineamentos propostos naqueles livros, a idéia de "desenvolvimento" e, por extensão, as possibilidades de "desenvolvimento sustentável". A terceira seção, por sua vez, se debruça mais diretamente sobre a palavra "sustentabilidade" e nesta parte os livros citados oferecem uma densa e variada discussão sobre os diversos

\footnotetext{
${ }^{2}$ Apenas como ilustração, usando-se o Google em inglês como mecanismo de busca, a palavra "sustainability" produz em alguns segundos quase cem milhões de entradas.

${ }^{3}$ Veiga escreveu inúmeros artigos (e outros livros), direta ou indiretamente relacionados ao tema geral. Consulte-se a respeito a sua página na internet: http://www.zeeli.pro.br.
} 
ângulos sob os quais sustentabilidade pode ser analisada. Finalmente, a quarta e última seção, que antecede uma sucinta seção dedicada às conclusões, escapa aos trabalhos de Veiga e sugere que os argumentos de outro autor, Eduardo Ehlers (cuja dissertação de mestrado foi ultimada sob a orientação de José Eli da Veiga), ainda parecem ser atuais e apropriados, em sua leitura sobre a "agricultura sustentável". Nesta seção, os argumentos principais de Ehlers são adiantados e discutidos (EHLERS, 1996).

\section{Sustentabilidade e desenvolvimento sustentável: ainda um valor a ser socialmente construído?}

Em seu livro de 2008, Veiga já apontava a importância da noção de "desenvolvimento sustentável" para o futuro da humanidade, sustentando um argumento que apresentara diversas vezes em artigos anteriores. Segundo suas palavras, trata-se, de fato, de um "generoso ideal", em alguma medida similar a certas "idéias-força" que surgem regularmente na história dos humanos e, quando expressam uma vontade coletiva mais ampla, acabam se disseminando e movendo iniciativas e esforços os mais diversos. Assim como o são as noções de justiça social, paz ou democracia, para não citar noções mais antigas como liberdade e igualdade, aquela é expressão que teria sido proposta e veio para ficar, estimulando uma "visão de futuro sobre a qual a civilização contemporânea necessita alicerçar suas esperanças" (VEIGA, 2008, p. 14). E analisando mais detidamente a expressão, mas sem a pretensão de elevar seu estatuto analítico à categoria de "conceito", o autor examina separadamente os argumentos, especialmente aqueles produzidos pela comunidade científica, sobre as suas partes componentes, "desenvolvimento" e "sustentável", abordagem que será seguida neste artigo, nas seções seguintes.

Já em sua obra mais recente, Veiga identifica uma sequência de significados para a palavra "sustentabilidade". Sugere que na década de 1970, embora ainda uma palavra mais restrita aos biólogos e à então emergente disciplina da Ecologia, 0 termo "sustentável" especificava, em especial, "a possibilidade de um ecossistema 
não perder sua resiliência, mesmo estando sujeito à agressão humana recorrente" (VEIGA, 2010, p. 11) ${ }^{4}$. Já no decênio seguinte, gradualmente a noção de sustentabilidade passou a ser associada e crescentemente "colada" ao termo desenvolvimento, o que foi consagrado no Relatório Brundtland e, sobretudo, alcançou enorme legitimidade mundial a partir dos resultados da "Conferência das Nações Unidas para o Meio Ambiente e o Desenvolvimento", realizada no Rio de Janeiro em junho de 1992. Catapultada por diversas iniciativas internacionais, especialmente pelo sistema das Nações Unidas, a expressão ganhou então terreno rapidamente e enraizou-se, cada vez mais, no linguajar corriqueiro de governos, das instituições, ONGs, autoridades e, aos poucos, até mesmo no cotidiano social. Apenas de sua ubíqua utilização, já no final dos anos noventa, nunca ganhou, de fato uma definição precisa e, em particular, "aplicável", o que poderia gerar processos e tecnologias associadas diretamente à expressão.

$\mathrm{Na}$ definição pioneira, que se tornou mundialmente conhecida, "desenvolvimento sustentável" seria aquele que "satisfaz as necessidades do presente sem comprometer a habilidade das futuras gerações de satisfazer suas próprias necessidades". Foi proposição que se mostrou desejável para todos, embora sem ter tido jamais um acordo sobre os processos que poderiam torná-la uma situação concreta. Na realidade, em sua simplicidade, é expressão que, concretamente, mais obscurece do que ilumina, pois implicitamente encobre diversas contradições em sua formulação.

Apenas como ilustração sobre a natureza problemática da novidade formulada, bastaria sugerir três claros e imediatos desafios que a expressão e suas discussões posteriores ainda não encontraram resposta (mas não discutidos nos livros citados). O primeiro deles diz respeito ao significado de "necessidades". Como essas mudam frequentemente ao longo do tempo, dentro de uma mesma sociedade, e comparativamente entre nações, parece mais do que improvável que as

\footnotetext{
${ }^{4}$ Resiliência é outro termo que foi ganhando popularidade e uso mais amplo. Talvez seja importante relembrar que se trata de um conceito originalmente usado na Física. Diz respeito à propriedade de alguns materiais que acumulam energia, mas não se rompem ou são destruídos, quando submetidos a formas de estresse significativas.
} 
necessidades das gerações futuras serão as mesmas necessidades das atuais gerações, o que implica que a própria definição de "desenvolvimento" também será modificada na mesma magnitude. Se o desenvolvimento atende, entre outros propósitos, as necessidades de uma determinada sociedade, então 0 "desenvolvimento sustentável”, logicamente, implicará também na dificuldade quase intransponível de refletir (e agir) sobre os recursos hoje existentes em função de necessidades futuras, se estas são largamente impossíveis de serem atualmente identificadas.

Outra contradição, associada à primeira, sugere que as necessidades são primordialmente definidas em termos culturais, mesmo as mais básicas e imediatas (como a alimentação, por exemplo). O consenso aparente e superficial em torno da expressão, que a torna tão popular e utilizada, funda-se, de fato, para alguns, em um silogismo problemático - enquanto outros até irão sugerir que se trata de uma falácia. Qual seja, o desenvolvimento sustentável pode ser desejável para todos (a partir da formulação original acima), mas pode ser definido sob forma muito diferente, nos termos de cada cultura específica. E, se for assim, como ter uma definição que seja pelo menos consensualmente aceita? A noção mais geral, portanto, pode ser superficialmente compartilhada, mas transposta para situações concretas, diferenças crescentes irão aflorar acerca de seu significado.

Finalmente, uma terceira dimensão mais geral também problematiza a idéia de desenvolvimento sustentável e diz respeito às prioridades e ao "processo" de sua construção social. Em outras palavras, diz respeito à pergunta: como estabelecemos qual ação ou conjunto de ações são mais sustentáveis (e, talvez, deveriam ser então priorizadas)? E relacionada a esta pergunta, surge outra imediata: o que deve ser sustentado? Por exemplo, assegurar padrões menos predatórios de recursos em detrimento de mais bem-estar da sociedade, rebaixando seus padrões de consumo? Ou este bem-estar deve ser sustentado, em detrimento do uso de recursos que são finitos?

Veiga não enfrenta diretamente esses desafios, mas encontra uma saída que é politicamente razoável, embora de longo prazo e, portanto, inaplicável em nossos dias. Sugere que muitas das críticas da "falta de um conceito" (similarmente a 
significados rigorosos que poderiam ser encontrados em termos, por exemplo, como "algarismos", "gravidade" ou "DNA") são consistentes e esperadas e, quem sabe, desenvolvimento sustentável, por longo tempo, poderá ser tão controverso quanto a noção de "justiça social". O que o autor enfatiza é que ao exprimir valores sociais que não são ainda consensualmente compartilhados, a dificuldade de encontrar definições precisas é previsível (VEIGA, 2010, p. 13). Em outras palavras, assim argumenta, a noção de desenvolvimento sustentável estaria mais próxima à trajetória de palavras e expressões gerais similares, as quais experimentaram trajetórias relativamente conturbadas em busca de seus significados mais amplamente aceitos. Como insiste, "o lema do desenvolvimento sustentável em muito se assemelha aos seus predecessores 'direitos humanos' e 'justiça social' (...) pois esforços normativos em 'conceituá-los' não conseguem superar certas dúvidas” (VEIGA, 2010, p. 37), arrematando ainda que

\begin{abstract}
um valor nunca é uma noção que possa ser bem definida, mesmo que seja unânime o reconhecimento de situações concretas em que ele foi contrariado. É inútil, portanto, tentar defender uma determinada concepção de sustentabilidade contra os abusos inerentes ao processo de banalização da idéia (VEIGA, 2010, p. 40).
\end{abstract}

\title{
3 As controvérsias em torno do "desenvolvimento"
}

O que significa desenvolvimento? Dificilmente uma palavra poderá ter observado uma trajetória tão intensamente disputada em uma época recente. Este foi debate que emergiu no pós-guerra e, desde então, vem observando uma fascinante história de controvérsias. Sinteticamente, seguindo novamente Veiga, existiriam algumas grandes vertentes, uma delas esposada pelo autor. Adianta que um primeiro grande grupo se prende, embora sob perspectivas que são, às vezes, terminologicamente diferenciadas, ao olhar sobre o desenvolvimento como sinônimo de crescimento e a ênfase, neste caso, se prenderá muito mais à discussão sobre os fatores e processos que estimulam ou bloqueiam o crescimento econômico. 
Como corolário, ocorre neste campo abundante produção de indicadores quantitativos, o mais difundido deles sendo a renda per capita. Outro grupo, em oposição a este primeiro foco, e ecoando leituras mais à esquerda, algumas vezes associadas a teorias sobre o imperialismo ou, ainda, sobre as relações desiguais entre nações, sugere que os discursos sobre o desenvolvimento, de fato, é ilusão ou mito ou, muitas vezes, aberta manipulação exercida por certos setores sociais.

Mas há um terceiro grupo, o qual, provavelmente, vem crescendo nas décadas mais recentes, que não aceita nem um lado e nem outro. Para esses, "o desenvolvimento nada tem de quimérico e nem pode ser amesquinhado como crescimento econômico" (VEIGA, 2008, p. 18). Sugere o autor, ainda, para a necessidade de "abrir" mais a noção de desenvolvimento e seus possíveis significados, pois "o intenso crescimento econômico ocorrido durante a década de 1950 em diversos países semi-industrializados não se traduziu necessariamente em maior acesso de populações pobres a bens materiais e culturais, como ocorrera nos países considerados desenvolvidos" (VEIGA, 2008, p. 19). Uma importante e decisiva inflexão, que veio contribuir notavelmente para aperfeiçoar o debate sobre $o$ significado do desenvolvimento ocorreu apenas na década de 1990, quando a ONU passou a divulgar o "Índice de Desenvolvimento Humano", popularizando cada vez mais os IDHs como indicadores de carências mais gerais, inclusive servindo como fonte de pressão sobre governos em todos os níveis. Como são indicadores que não se restringem unicamente às mensurações sobre a renda e sua distribuição, o IDH lentamente foi se afirmando como uma aproximação mais razoável sobre o desenvolvimento alcançado em determinada região ou sociedade, também contribuindo para ir sepultando a primeira perspectiva antes sugerida - aquela que defendia desenvolvimento como sendo equivalente apenas ao crescimento econômico.

Esta última perspectiva se inspira em muitos fatores, mas o autor cita como uma fonte teórica relevante o trabalho de um dos mais importantes economistas brasileiros, Celso Furtado, citando-o como um pioneiro observador que também 
criticou a correspondência que muitos vinham fazendo entre desenvolvimento e crescimento. Segundo Furtado,

\begin{abstract}
o crescimento econômico, tal qual o conhecemos, vem se fundando na preservação dos privilégios das elites que satisfazem seu afã de modernização; já o desenvolvimento se caracteriza pelo seu projeto social subjacente. Dispor de recursos para investir está longe de ser condição suficiente para preparar um melhor futuro para a massa da população. Mas quando o projeto social prioriza a efetiva melhoria das condições de vida dessa população, o crescimento se metamorfoseia em desenvolvimento (apud VEIGA, 2008, p. 81).
\end{abstract}

Sob a ótica deste terceiro grupo de estudiosos, Veiga enceta vigorosa crítica ao uso do PIB como indicador da "saúde econômica" de um país, alegando ser este um parâmetro que apenas agrega "a soma (em valores monetários) de todos os bens e serviços produzidos para o mercado num determinado período" (VEIGA, 2010, p. 19), o que introduz uma séria limitação ao seu uso, pois "não há distinção entre os que são ou não benéficos para a sociedade. Despesas com acidentes, poluição, contaminações tóxicas, criminalidade ou guerras são consideradas tão relevantes quanto investimentos em habitação, saúde, ou transportes públicos" (Ibid, p. 118). Além disto, esta é distinção que requer que "velhas ortodoxias" sejam reanalisadas criticamente e, para tanto, cita, como exemplo, a discussão entre "desenvolvimento e distribuição de renda", resgatando a contribuição de um conhecido economista, Simon Kuznets, que foi, inclusive, agraciado com o Nobel de Economia (1971). Kuznets, assegura Veiga, usou dados disponíveis nos anos cinquenta para formular a hipótese de que "a desigualdade de renda tendia a aumentar na fase inicial da industrialização de um país, ocorrendo o inverso na fase posterior, quando esse país estivesse desenvolvido" (VEIGA, 2008, p. 43). Mas, segundo Veiga, as evidências disponíveis na ocasião eram fortemente precárias e, mesmo assim, o teorema proposto por Kuznets vigorou por aproximadamente quatro décadas como sendo verdadeiro, e somente em anos mais recentes vai sendo substituído por um novo "consenso emergente", aquele que nos informa que, pelo contrário, a distribuição de renda é solidamente persistente, independentemente da desenvoltura do crescimento econômico (VEIGA, 2008, p. 43-45). 
Já a tese que aponta o "desenvolvimento como quimera" é bem ilustrada em seu livro pelas contribuições de um economista e sociólogo marxista italiano, Giovanni Arrighi, cuja pergunta central residia em "saber se seria possível algum tipo de mobilidade ascendente na rígida hierarquia da economia capitalista mundial" (Ibid, p. 20). Para respondê-la, Arrighi utilizou na sua argumentação os dados da distribuição do PNB per capita entre os anos de 1938 e 1983, demonstrando que padrões de mobilidade ascendente foram exceções notáveis, assim insistindo na rigidez da segmentação entre os países e concluindo ser praticamente impossível modificar este quadro de relações entre as nações do planeta. José Eli da Veiga, contudo, seguindo no veio de recusar indicadores como o PNB como satisfatórios, critica Arrighi em suas conclusões, exatamente por seguir, como outros, a equivalência entre crescimento e desenvolvimento. Em suporte às suas reflexões, Veiga cita um diplomata peruano, Oswaldo Rivero, que escreveu criticamente sobre o mesmo tema, argumentando que aquelas seriam visões meramente quantitativas do processo de desenvolvimento, ao minimizar outras dimensões estruturais, culturais, sociais e ecológicas. Aquele analista sugere que fenômenos de pobreza (e, portanto, de "não desenvolvimento") decorreriam de altas taxas de crescimento demográfico associadas à exportação de bens com baixo valor agregado, sugerindo políticas de redução de nascimentos e a modernização tecnológica da produção (VEIGA, 2008, p. 25-26).

Celso Furtado reaparece neste debate, ainda seguindo o comentário crítico de Veiga, quando sustentou que "as economias periféricas nunca serão desenvolvidas, no sentido de similares às economias que formam o centro do sistema capitalista", ainda salientando que a correspondência entre crescimento e desenvolvimento desvia as "atenções da tarefa básica de identificação das necessidades fundamentais da coletividade" (apud VEIGA, 2008, p. 28). O comentário é reforçado com as idéias de Fernando Henrique Cardoso, que insiste que os conceitos tem uma "datação histórica" e demandam sua atualização sistemática, de acordo com as transformações na história das nações e, como resultado, "as novas dimensões ecológicas, e até éticas, por exemplo, enriqueceram 
as noções de desenvolvimento" (apud VEIGA, 2008, p. 32). Tais ressignificações, alerta o autor, gradualmente forçaram a novas análises sobre o tema, indicando que "as políticas de desenvolvimento deveriam ser estruturadas por valores, que não seriam apenas os da dinâmica econômica" (VEIGA, 2008, p. 32).

Mas foi o indiano Amartya Sen, também laureado com o Nobel (em 1998), que iria expor claramente um novo foco para se entender a noção de desenvolvimento, criando as bases analíticas para os autores que vêm se situando no emergente "terceiro grupo" antes citado. Os trabalhos de Sen demonstraram "a necessidade de se reconhecer o papel das diferentes formas de liberdade no combate às absurdas privações, destituições e opressões" (Ibid, p. 33) consequentemente, a expansão da(s) liberdade(s) gozadas pelos cidadãos seria o principal fim e também o principal meio do desenvolvimento. O desenvolvimento demandaria, sugeriu o autor indiano analisado no livro de Veiga, que sejam removidas as principais fontes de privação da liberdade: a pobreza, a tirania, a carência de oportunidades, a destituição social, a negligência dos serviços públicos e a intolerância política do Estado. Se removidas, os indivíduos ampliariam suas "capacidades", em especial aquelas quatro consideradas como as fundamentais, que foram assim indicadas: ter uma vida longa e saudável, ter acesso à instrução, acessar recursos para ter uma vida digna e, finalmente, participar da vida comunitária. Assim entendido, seria inevitável que todo 0 debate sobre 0 desenvolvimento, a partir da densa e inovadora contribuição de Amartya Sen, sofresse uma inovadora inflexão.

O papel das formulações de Sen, no entanto, foi muito além, pois influenciou decisivamente a construção de indicadores no âmbito do PNUD, a partir do início da década de 1990, assim como a própria definição de desenvolvimento, que foi então difundido, se relacionando "primeiro, e acima de tudo, com a possibilidade de as pessoas viverem o tipo de vida que escolheram, e com a provisão dos instrumentos e das oportunidades para fazerem as suas escolhas" (apud VEIGA, 2008, p. 81). Foram reflexões que estiveram nos fundamentos interpretativos que acabaram levando à formulação dos IDHs, os quais, por sua vez, revolucionaram a ótica sob a 
qual os governantes e os cidadãos passaram a ver o estado geral de suas próprias sociedades. Esses indicadores, embora tenham representado um extraordinário avanço na compreensão sobre o desenvolvimento, para Veiga, no entanto, ainda necessitam ser aperfeiçoados. Para o autor, o "principal defeito do IDH é que ele resulta da média aritmética dos três índices mais específicos que captam renda, escolaridade e longevidade" (VEIGA, 2008, p. 88). Assim, uma das variáveis pode isoladamente influenciar o IDH - por exemplo, a renda pode ser mais alta, elevando - IDH, mas a escolaridade e a longevidade podem ser ainda baixas, revelando grandes precariedades sociais. Quando listada, a classificação entre municípios, por meio do "IDH Município" (IDH-M) tais contrastes são evidenciados. Conclui que existe uma óbvia necessidade de aprimorar a proposta, criando novos indicadores, sem perder, no entanto, a essência conceitual dos IDHs.

Veiga conclui sua discussão sobre o "ideal do desenvolvimento" e a síntese das controvérsias em torno desta noção sugerindo algumas formas mais abrangentes de se aproximar empiricamente do significado de desenvolvimento. Comenta sobre duas formas de mensuração desenvolvidas no Brasil, o "Índice Paulista de Responsabilidade Social" e o "DNA Brasil", este último proposto pela Unicamp, e sugere que são propostas analíticas mais ambiciosas do que a metodologia dos Índices de Desenvolvimento Humano. Mas, como comentário final, que é relevante para os objetivos deste artigo, Veiga admite que o maior obstáculo para perceber o fenômeno do desenvolvimento empiricamente (e, portanto, "mensurá-lo") está justamente na "natureza necessariamente multidimensional do processo de desenvolvimento. Ela sempre tornará muito duvidoso e discutível qualquer esforço de se encontrar um modo de mensuração que possa ser representado por um índice sintético" (VEIGA, 2008, p. 105).

\section{Sustentabilidade: requer um novo padrão civilizatório?}


E o outro termo da expressão - padeceria "sustentabilidade" das mesmas contradições, para além daquelas citadas sucintamente na primeira seção deste artigo? Para o autor que aqui inspira e sustenta a discussão sobre desenvolvimento sustentável, o significado da noção de "sustentabilidade" foi mais discutido em dois campos científicos, a Ecologia e a Economia. Mas apenas a primeira determinou claramente as fronteiras do tema, consolidando a partir desta delimitação a sua agenda de pesquisa específica. Para a Ecologia, sustentabilidade não encerra maiores desafios de interpretação, pois significa a "capacidade que tem um sistema de enfrentar distúrbios mantendo suas funções e estrutura. Isto é, sua habilidade de absorver choques, adequar-se a eles e, até mesmo, deles tirar benefícios, por adaptação e reorganização" (VEIGA, 2008, p. 17).

No campo da teoria econômica, contudo, permanecem quase ilimitadas diferenças de interpretação e, talvez, existam três conjuntos de esforços que podem ser identificados: uma perspectiva convencional, outra ecológica e um ainda difuso terceiro grupo, o qual, na realidade, insatisfeito com os dois primeiros focos, procura uma terceira via de entendimento sobre o problema. O campo convencional é simbolizado pela "curva de Kuznets ambiental", após uma correlação que foi primeiramente proposta em 1992 por dois economistas, Gene Michael Grossman e Alan Krueger, em artigo publicado no "Quarterly Journal of Economics". É a proposta analítica majoritária e ainda amplamente dominante, embora sob uma barragem de críticas que apenas vêm se avolumando nos anos mais recentes (ver, por exemplo, STERN, 2004). O modelo sugere que a existe uma curva na forma de um " $U$ invertido", relacionando crescimento econômico e degradação ambiental e, desta forma, após uma gênese negativa, existiria uma recuperação ambiental a partir de um certo patamar de desempenho econômico, "passando a ocorrer mais melhorias ambientais do que deterioração, ao contrário do que ocorria em fases anteriores, quando o crescimento econômico não podia ser influenciado por preocupações com a proteção com os ecossistemas. Por isso, o melhor caminho para se conseguir a sustentabilidade seria maximizar o crescimento econômico por toda a parte" (VEIGA, 2010, p. 22, ênfase adicionada). Em termos mais simples e em analogia com outra 
discussão conhecida na história brasileira, seria preciso primeiramente crescer, para posteriormente recuperar os impactos ambientais, o que o crescimento econômico faria "naturalmente" (VEIGA, 2008). Como a noção de crescimento, para os autores deste grupo é meramente indicada pela renda per capita, Veiga insiste que este ponto de partida já inviabiliza a potencialidade analítica proposta por aqueles autores.

Outra perspectiva deste debate, chamada de "ecológica" tem a sua origem em um autor bastante controvertido na história do pensamento econômico, Nicholas Georgescu Rogen, o qual, desde 1971, e inspirado em estudos da termodinâmica, começou a alertar para o "inexorável aumento da entropia". Em síntese, a sua contribuição afirma que "as atividades econômicas gradualmente transformam energia em formas de calor tão difusas que são inutilizáveis. A energia está sempre passando, de forma irreversível e irrevogável, da condição de disponível para não disponível. Quando utilizada, uma parte da energia de baixa-entropia (livre) se torna de alta entropia (presa)" (VEIGA, 2008, p. 111). Um exemplo desta tendência seria a extração da baixa entropia contida no carvão e no petróleo (VEIGA, 2008, p. 112) exigido pelo crescimento econômico moderno e com resultados de crescente insustentabilidade. É também por esta razão que as teses deste autor, assim como aquelas de seus (poucos) seguidores, tem sido recebidas como sendo radicalmente céticas e pessimistas em relação aos padrões de crescimento observados no Ocidente mais avançado, em especial durante a segunda metade do século passado.

Herman E. Daly, embora participante deste segundo grupo de uma teoria ecológica, propôs uma versão menos pessimista do modelo de Georgescu Rogen, argumentando que somente haveria uma alternativa à inevitável decadência ecológica dos sistemas econômicos e produtivos, e esta seria a chamada "condição estacionária”, sob a qual a economia continuaria a aperfeiçoar-se apenas em termos qualitativos, abolindo a dimensão quantitativa do crescimento (substituindo, por exemplo, energia derivada de combustível fóssil por outras fontes de "energia limpa”). Como resultado, segundo Daly, "o crescimento da população e da produção não deve levar a humanidade a ultrapassar a capacidade de regeneração dos recursos e da absorção de dejetos" (apud VEIGA, 2008, p. 130). Portanto, o 
verdadeiro significado da sustentabilidade seria "o desenvolvimento sem crescimento", pois "o processo econômico em que se baseia o progresso humano é mera transformação de recursos naturais valiosos (baixa entropia) em resíduos (alta entropia)" (VEIGA, 2010, p. 36). Para ilustrar esses processos, Daly propõe uma curiosa, mas instigante ilustração, comparando o estado das modernas economias do capitalismo avançado a

\begin{abstract}
uma biblioteca que já está repleta de livros, sem espaços para novas aquisições. A melhor solução é estabelecer o princípio de que um novo livro só poderá entrar no acervo quando outro for retirado, numa troca que só seria aceita se o novo livro fosse melhor que o substituído. Ou seja, no 'estado estacionário' a economia continuaria a melhorar em termos qualitativos, substituindo, por exemplo, energia fóssil por energia limpa. Mas seria abolida nessas sociedades mais avançadas a obsessão pelo crescimento do PIB (apud VEIGA, 2008).
\end{abstract}

Como seria provavelmente esperado, as idéias de Daly foram severamente criticadas, sob diferentes argumentos, variando entre aqueles que afirmam que qualquer tipo de condição estável é incompatível com a própria lógica imanente do sistema capitalista àqueles que, mais exageradamente, até sugerem que o modelo proposto contraria os ideais da democracia e as possibilidades de escolha livre dos cidadãos (VEIGA, 2010, passim).

Confrontados com este binômio analítico intransponível, alguns economistas, por considerarem a primeira via inconsistente com as emergentes questões ambientais e a segunda via impraticável, vêm procurando estabelecer uma "terceira via", na qual se apostaria em uma "progressiva reconfiguração do processo produtivo, na qual a oferta de bens e serviços tenderia a ganhar em ecoeficiência: desmaterializando-se e ficando cada vez menos intensiva em energia. A economia poderia, assim, continuar a crescer sem que limites ecológicos fossem rompidos, ou que recursos naturais viessem a se esgotar" (VEIGA, 2010, p. 24). Seria, em decorrência, um caminho do meio entre o otimismo dos convencionais e o pessimismo dos ecológicos. No entanto, essa tese foi contestada pelo relatório "Prosperity without Growth ?", o que acabou aumentando o poder da tese dos ecológicos. Esse relatório, a partir de evidências históricas sobre o uso de energia e 
minerais, demonstra que ganhos de eficiência, de fato, não reduzem escalas. E que não há, necessariamente, redução absoluta do consumo mesmo ocorrendo queda de intensidade ecológica por unidade de produto. Ocorre em maior frequência exatamente o contrário. Ou seja, o "uso de poupanças obtidas pela redução da intensidade tende a elevar 0 consumo, mediante investimentos em outras atividades" (VEIGA, 2010, p. 27).

Desta forma, afirma Veiga, a sustentabilidade somente será uma meta alcançável se reconhecer os limites naturais à expansão das atividades econômicas e romper com a lógica social do consumismo, assim confrontando o próprio padrão civilizatório hegemônico. Destacando ainda a sua preocupação com a capacidade destruidora adquirida pela espécie humana ao longo da história.

A conclusão mais saliente de suas leituras é, portanto, inevitável e inescapável. As concepções passadas sobre o desenvolvimento demandam inelutavelmente um novo requisito de ajustamento - a sustentabilidade ambiental. "Trata-se de um imperativo global que chegou para ficar, em virtude da percepção de que a biosfera, em níveis global, regional, nacional e local, está sendo submetida a pressões insuportáveis e prejudiciais para o próprio desenvolvimento e as condições de vida" (VEIGA, 2008, p. 187). Portanto, a "necessidade de se colocar o qualificativo 'sustentável' reflete, em última instância, o crescente esgotamento de um dos principais valores dos tempos modernos, e não uma mera insuficência da noção de desenvolvimento" (ibid, p. 192, ênfase adicionada). Ou seja, em outras palavras, José Eli da Veiga, como conclusão central de suas reflexões sobre o desenvolvimento sustentável, acaba defendendo que a emergência de um novo padrão societário assentado na sustentabilidade, se e quando ocorrer, somente será materializado sobre um novo conjunto de valores compartilhado pelos cidadãos, o que muda radicalmente o campo de expectativas sobre tais noções.

Saliente-se, por fim, que o autor também discute as formas de medição da sustentabilidade, novamente comparando diversos índices já propostos e sendo testados em diferentes instituições (VEIGA, 2008, p. 170-184). Mas mantendo também aqui também algum ceticismo a respeito, pois confrontado com as 
insuficiências analíticas da expressão: se "desenvolvimento" encontra tantas controvérsias e pendências analíticas, a adjetivação "sustentável", como decorrência, encontrará iguais ou maiores desafios. No entanto, ainda que os índices já operando encontrem grandes limitações, o autor lembra que "mesmo que ainda esteja longe o surgimento de uma medida mais consensual de sustentabilidade ambiental, é imprescindível entender que os índices e indicadores existentes já exercem papel fundamental nas relações de fiscalização e pressão que as entidades ambientalistas devem exercer sobre as governos e organizações internacionais" (VEIGA, 2008, p. 182).

\section{E a agricultura sustentável?}

Se os dois livros especialmente revisados acima, sob a lavra de José Eli da Veiga, não discutiram diretamente o tema, mais setorial, da "agricultura sustentável", seu orientando na USP, Eduardo Ehlers, o fez com brilhantismo, trabalho posteriormente publicado na forma de livro (EHLERS, 1996). Este é um estudo que, simplificadamente, apresenta três grandes partes: no início, Ehlers comenta mais genericamente sobre as diferenças entre a chamada "agricultura moderna" e as visões contestadoras do formato tecnológico dominante nas agriculturas do mundo. Posteriormente, apresenta as características mais destacadas que identificam o que intitulou de "movimentos rebeldes", ou seja, aqueles esforços realizados, em diferentes partes do mundo, de desenvolver as bases de uma "outra agricultura", sob diferentes denominações, as quais pudessem servir de fundação para novos arranjos tecnológicos que se contrapusessem à agricultura moderna. $E$ na terceira parte, mais breve, porém esclarecedora, o autor comenta sobre as possibilidades reais de aquelas propostas alternativas vingarem no mundo real das atividades produtivas agropecuárias.

Sinteticamente, o autor desta pesquisa específica sobre a agricultura alerta que foi durante as décadas de 1970 e a seguinte que se observou o crescimento de diversas iniciativas que se apresentaram como um "contraponto tecnológico" ao 
formato organizativo da agricultura que surgiu no pós-guerra e disseminou-se pelo mundo, sendo implantado no Brasil com vigor em algumas regiões nos anos da modernização dos anos setenta. Este formato, que singulariza o que a literatura viria a chamar de "agricultura moderna", desencadeou inúmeras consequências ambientais, como o desmatamento, a erosão dos solos e a contaminação química dos recursos naturais e dos alimentos. Inicialmente, aqueles esforços contestadores foram chamados de "alternativos" e desencadearam algumas tentativas (especialmente do campo das ONGs) de desenvolver e propor às famílias rurais recomendações tecnológicas entendidas como inovadoras, além de novas formas de manejo de recursos naturais.

Foi somente no final da década de 1980 que a adjetivação foi modificada, emergindo a expressão "agricultura sustentável" para identificar aqueles mesmos propósitos. Mas é designação que ainda permanece comprometida por inúmeras dúvidas e contradições. Agricultura sustentável, por exemplo, englobaria todas as tendências que compunham o campo de esforços da "agricultura alternativa", entre os anos setenta e oitenta? Ou indicaria processos de "transição produtiva", um movimento gradual de passagem dos formatos intensivos da agricultura moderna para outros padrões tecnológicos que absorvam menores quantidades (em volume e valor) de insumos agroindustriais - ou seja, significando um abrandamento gradual das características economicamente mais marcantes da agricultura moderna? Ou seria ainda um esforço radical de construir um padrão radicalmente diferente, uma "outra agricultura"? O estudo de Ehlers, neste sentido, embora realizado vinte anos atrás, é ainda convincente para demonstrar que as respostas àquelas perguntas permanecem sem respostas (e nem mesmo a expressão "agroecologia", que sequer é citada no livro, também responde às mesmas indagações).

O autor, após descrever sinteticamente os ingredientes factuais principais da história tecnológica que entre o final do Século XIX e as primeiras décadas do século seguinte montaram o padrão moderno de agricultura, apresenta então na segunda parte os chamados "movimentos rebeldes", as iniciativas de contestação que foram sendo desenvolvidas em contraposição àquele padrão. Foram, sobretudo, 
iniciativas de movimentos que valorizam potenciais biológicos dos processos produtivos, mas com diversas vertentes e, por consequência, elaboraram requisitos específicos e recomendações detalhadas, muitas ancoradas em orientações filosóficas que as sustentavam. As vertentes de agricultura chamadas de biodinâmica, orgânica e biológica surgiram na Europa, enquanto outra escola, a agricultura natural, surgiu no Japão. Tais movimentos se mantiveram marginalizados da produção agrícola e da comunidade científica agronômica, ou por opção própria ou, então, porque jamais encontraram espaços institucionais para serem apresentados e debatidos.

Foi especialmente na década de 1970 que a evidenciação crescente dos efeitos negativos do padrão moderno de agricultura se avolumou e esses movimentos, como eram alternativos ao primeiro, encontraram maior visibilidade. Para essas iniciativas por fora do establishment, o padrão moderno passou a ser denominado de "convencional", e o conjunto de propostas relacionadas com os ditos movimentos passou a ser denominado de "alternativo". Na década seguinte foi intensificado o interesse por essas propostas e práticas alternativas, tanto por parte de ambientalistas como por parte de pequenos grupos de consumidores, assim como cresceu o interesse por setores, ainda reduzidos, da pesquisa agronômica, pois foi despertado o interesse em métodos de produção capazes de reduzir o uso de insumos industrializados e o consumo de energia fóssil, contexto que foi largamente estimulado, já no final dos anos oitenta, pela difusão da noção geral de sustentabilidade.

Similarmente à busca de melhor compreensão sobre os significados de "desenvolvimento" e de "sustentabilidade", antes discutidos, nos últimos vinte anos, em especial, têm sido intensificados os esforços para decifrar, em termos práticos, o significado da "agricultura sustentável". Originalmente, se imaginava, conforme propõe o estudo de Ehlers, que o desafio de conceituar e estabelecer "critérios" (ou indicadores) de uma agricultura sustentável seria menos complexo do que compreender o desenvolvimento sustentável. Seu trabalho, contudo, mesmo tendo sido realizado duas década atrás, demonstra que este desafio, presente naquele 
momento (a primeira metade dos anos noventa) ainda permanece em nossos dias. Ou seja, usualmente as iniciativas continuam transitando entre dois polos muito distantes, quase irreconciliáveis entre si: em um extremo, posições fortemente moderadas (ou até conservadoras) que entendem ser a agricultura sustentável nada mais do que um ajuste ou um aprimoramento focalizado e pontual da agricultura moderna, estabelecendo melhor manejo de recursos naturais e a montagem de uma agricultura "eco-eficiente" (KEATING et al, 2010), desta forma suavizando os impactos ambientais desta atividade econômica. No outro extremo, existem outras posições, altamente idealizantes e românticas (e explicitamente anticapitalistas), que julgam factíveis a ocorrência de uma série de "mudanças estruturais" associadas a uma radical transformação do padrão tecnológico da agricultura moderna, implicando até mesmo em novas relações sociais e políticas que conformarão um novo padrão societário. No Brasil, o que não é discutido por Eduardo Ehlers, o debate (e os esforços, inclusive no campo da pesquisa agrícola) que é abrigado sob o guardachuva do termo "agroecologia", em anos mais recentes, reflete, em larga medida, essas mesmas imprecisões, o que traz para este campo de contestação à agricultura moderna exigências urgências vastas e complexas, o primeiro desafio sendo, talvez, um entendimento prévio sobre o que está se discutindo e propondo mantendo-se que seja possível esta convergência de propósitos entre seus proponentes.

\section{Conclusões}

Este artigo pretendeu oferecer uma sistematização de algumas das principais facetas de um debate relacionado, no final, à agricultura sustentável e seus possíveis significados. Para tanto, este exercício fundou-se na bibliografia de um autor referencial neste campo, José Eli da Veiga e, em especial, em dois de seus livros recentemente publicados que lidaram com os "antecedentes" lógicos que preparam o campo para a discussão sobre a agricultura sustentável: os termos "desenvolvimento" e "sustentabilidade". 
Uma síntese das principais conclusões extraídas da análise aponta a imensa dificuldade analítica e operacional ainda existente para se chegar a algum "consenso mínimo", seja sobre o significado de um processo social e econômico englobado pela palavra desenvolvimento ou, então, igualmente pela palavra sustentabilidade e pela expressão agricultura sustentável. Sobre o desenvolvimento, Veiga parece concordar com a abordagem de Sen e também com a sugestão de identificar o desenvolvimento como um processo que exigirá um rompimento sobre o padrão civilizatório difundido no mundo, tendo como momento estimulador os anos de expansão que se seguiram à Segunda Guerra Mundial, período que cimentou aquele padrão organizativo das sociedades. Se for assim, trata-se de visão que, em termos históricos, ainda se encontra sob um foco utópico, pois parece improvável que em algum tempo razoável as sociedades encontrarão uma fórmula civilizatória que prescinda do crescimento econômico como seu motor principal. E, no tocante à sustentabilidade, o autor sugere que se trata de um "valor social", o que implica em desafios ainda mais gigantescos. A história da formação das sociedades, que necessariamente se assenta em valores sociais, demonstra que a materialização de novos valores (e, neste caso, implicando em drásticas alterações das práticas sociais, em todos os âmbitos) somente ocorre em processos de longa duração e exigem circunstâncias muito específicas para encontrarem campo fértil à sua consolidação e posterior orientação dos comportamentos sociais.

Por fim, as considerações centradas na discussão sobre agricultura sustentável, ao final, igualmente são suficientes para alçar a posição de relevo os iguais (e enormes) desafios que esta idéia geral e ainda largamente imprecisa impõe aos protagonistas sociais que buscam construir outros formatos tecnológicos em contraposição à atual dominação da chamada agricultura moderna. Com realismo, parece improvável que esta construção social possa ser observada em tempo histórico de médio prazo e, pelo contrário, todas as evidências sugerem que, quando muito, a noção de sustentabilidade, quando aplicada aos sistemas produtivos agropecuários, exigirão, cada vez mais, o conhecimento tecnológico e as visões de ciência hoje existentes para abrir novos caminhos produtivos que, gradualmente, 
possam alcançar "mais com menos", ou seja, mais produção de alimentos e matérias-primas de origem agropecuária, com qualidade, com menos utilização de terram água, nutrientes, energia, trabalho e capital. Se este objetivo, que parece, em princípio, modesto e limitado, mas pelo contrário compreende requerimentos tecnológicos de extrema complexidade, hoje ainda inexistentes, for alcançado em tempo histórico razoável, largos e positivos passos já terão sido dados para aprimorar substantivamente a mais antiga atividade econômica dos humanos.

\section{Referências}

EHLERS, Eduardo. Agricultura sustentável: origens e perspectivas de um novo paradigma. São Paulo: Livros da Terra, 1966.

KEATING, Brian A. et al. Eco-efficient agriculture: concepts, challenges and opportunities. In: Crop Science, number 50, p. 109-119, 2010.

STERN, D. The Rise and Fall of the Environmental Kuznets Curve. World Development, v. 32, n. 8, p.1419-1439, 2004.

VEIGA, José Eli da. Desenvolvimento sustentável. O desafio do século XXI. Rio de Janeiro: Garamond, 2008.

. Sustentabilidade. A legitimação de um novo valor. São Paulo: SENAC, 2010. 